\title{
Desigualdad social en el período Tardio: manifestaciones espaciales y materiales en el poblado El Carmen 1, provincia de Tucumán
}

\section{( Violeta Cantarelli*}

\author{
Fecha de defensa: 10 de julio de 2017 \\ Director: Dr. Javier H. Nastri \\ Jurados: Dres. Andrés Laguens, Laura \\ Quiroga y Verónica Williams
}

\section{Introducción}

Esta tesis tiene como propósito contribuir al conocimiento sobre la organización social de las poblaciones agropastoriles durante el período Tardío en el sector medio del valle de Santa María. El objetivo consiste en detectar las manifestaciones espaciales y materiales de la desigualdad social en el poblado El Carmen 1, situado geográficamente en la falda oriental de la sierra del Cajón en la provincia de Tucumán.

Las investigaciones realizadas se apoyan en la coyuntura sociopolítica conocida para este período temporal, caracterizado por una complejidad social creciente, una intensificación económica en un contexto de conflicto generalizado y un aumento demográfico con mayor inversión en la infraestructura productiva a una escala desconocida en los períodos previos. De la mano de estos procesos, emergieron grandes poblados conformados por conglomerados situados sobre mesetas, laderas y terrazas altas, desde los cuales sus pobladores podían controlar y vigilar amplios territorios desde los pukaras. Frente a condiciones de creciente competencia y conflicto entre los grupos, se desenvolvió un proceso político en el cual se manifestaron prácticas asociadas al ejercicio del poder. Este proceso se relacionó con el surgimiento de entidades sociopolíticas centralizadas con características semejantes a las jefaturas, que además presentaban distintos niveles en la jerarquía de sus asentamientos. Fundamentalmente, se planteó la existencia de desigualdad y estratificación social a partir del establecimiento de un segmento social que controlaba las diversas actividades sociales y manejaba la producción, distribución y consumo de bienes confeccionados por artesanos a su servicio. Su poder dentro de la sociedad se consolidaba a través del consumo de bienes o artefactos de prestigio con significativo valor social. Durante el período Tardío, las poblaciones ocupaban el territorio siguiendo un modelo de organización social

* Departamento de Ciencias Naturales y Antropológicas, Centro de Estudios Biomédicos, Biotecnológicos, Ambientales y de Diagnóstico (CEBBAD), Universidad Maimónides - CONICET, Hidalgo 775, piso 7 (CP C1405BCK), Ciudad Autónoma de Buenos Aires, Argentina. E-mail: violeta.cantarelli@fundacionazara.org.ar jerarquizado, en el cual la distancia social respecto al curaca se materializaba en la distancia física (Tarragó, 1987, 1999).

Sobre la falda occidental del extenso valle de Santa María se documentaron asentamientos de poblaciones con diferenciación de sectores. En dirección sur-norte se destacan Cerro Mendocino-Punta de Balasto, Rincón Chico, Fuerte Quemado, Quilmes, Tolombón y Pichao. El poblado El Carmen 1 se localiza en una latitud cercana al asentamiento de Fuerte Quemado, a unos 7 km en dirección Oeste. Preliminarmente se caracterizó como un centro poblado secundario en el marco de sociedades que articulaban distintas instalaciones funcionalmente complementarias en su patrón de asentamiento (Nastri, 1997-1998). Con el avance de las investigaciones se determinaron diferencias funcionales entre los sectores a partir de la morfología de las plantas, los tamaños, la variabilidad de los elementos arquitectónicos presentes y sus localizaciones en el poblado (Coll, Cantarelli y Nastri, 2015).

El poblado El Carmen 1 se fundó sobre las quebradas El Carmen y El Carrizal, en un terreno completamente irregular que alcanza las 100 hectáreas, considerando los espacios sin construcciones formales. Sus pobladores construyeron sobre cimas, crestas de cimas, laderas y sectores bajos. De modo que se establecieron 15 sectores ( I al XV), mayoritariamente ubicados en la quebrada El Carmen. Del conjunto total se distingue al sector VI por su tipo de emplazamiento y localización. El mismo se sitúa en la cima más amplia (4.00o $\mathrm{m}^{2}$ ) y elevada (2.400 m s.n.m) sobre una posición central entre las quebradas El Carmen y El Carrizal. Esta distinción conduce a indagar acerca del segmento social allí residente que aparentemente se encontraba desligado de las tareas productivas por su segregación espacial, sin embargo, contaba con la facilidad de comunicarse con los habitantes de las dos quebradas.

A partir de los primeros resultados obtenidos se asume como supuesto que la jerarquía política, en términos organizacionales, suponía la existencia de desigualdades y estratificación social efectiva. Un pequeño sector social se ocupaba del control y la administración de las actividades sociales como producción, distribución y consumo. En consideración con el supuesto asumido, el objetivo principal de esta tesis es detectar las manifestaciones espaciales y materiales de la desigualdad social a partir 
del estudio de tres sectores del asentamiento emplazados sobre topografías dispares. De esta manera, la elección de los sectores I (pie de cerro de quebrada El Carmen), VI (cima entre quebradas) y XII (faldeo de quebrada El Carrizal), permitiría poner a prueba la existencia de manifestaciones espaciales y materiales de la desigualdad social mediante la variabilidad del trazado espacial y de la cultura material -mueble e inmueble- en sectores funcional y topográficamente diferentes. A partir de las muestras de carbón recuperadas en las excavaciones de los sectores I y VI del asentamiento se estableció la ocupación sincrónica de los mismos durante el período Tardío (Coll et al., 2015). Asimismo, a partir de los resultados de los relevamientos arquitectónicos y del análisis y procesamiento de las muestras cerámicas recuperadas en superficie en el sector XII, se determinó su ocupación durante tiempos tardíos, siendo de esta manera contemporáneo a los conjuntos de la quebrada El Carmen.

\section{Resultados}

Como consecuencia del estudio de las manifestaciones espaciales y materiales en los sectores I, VI y XII en el poblado El Carmen 1 se sostuvo la existencia de una organización social basada en la desigualdad. Las evidencias obtenidas llevaron a proponer que los habitantes del sector VI habrían ocupado un rol central en la organización social del asentamiento. En tanto que habrían controlado la circulación interna entre las quebradas y el intercambio de productos que se habría desarrollado entre sus habitantes. De esta manera, conformarían un segmento social selecto residente en la pampa de altura más elevada del poblado. Al mismo tiempo, su localización constituiría una opción estratégica y simbólicamente significativa dentro de la cosmogonía de las sociedades andinas (Lorandi y De Hoyos, 1995). Al sector VI se accedía por medio de las dos quebradas - El Carmen y El Carrizal — artificialmente defendidas y los caminos habrían estado monitoreados por los habitantes de la cima que poseían un completo control del entorno hacia los cuatro puntos cardinales. Por otro lado, en esta zona específica del paisaje, se construyeron principalmente recintos en los cuales se empleó la técnica constructiva del muro simple con doble lienzo con relleno o entrecruzado. Algunos muros presentan en sus superficies internas los cantos alineados. Asimismo, las vasijas que circulaban entre los habitantes de la cima consistían principalmente en estilos conocidos y definidos para el valle durante el período Tardío. También se pudo constatar la manipulación de vajilla de servicio elaborada con pasta fina y compacta. Hasta aquí se enumeraron una serie de características distintivas que facilitan la ilustración del grupo social residente.

En contraste con la localización topográfica del conjunto anterior, el sector I se sitúa al pie del cerro en la entrada de la quebrada El Carmen sobre una zona terrestre deprimida. Si bien no se percibe desde el río seco que desciende de la quebrada homónima, el conjunto arquitectónico que conforma al sector se encuentra desprotegido natural y artificialmente. Desde su posición se accede a una cuenca visual limitada por su emplazamiento. Es posible apreciar parte del valle de Santa María y el entorno sobre el cual se sitúan el resto de los sectores de ambos lados de la quebrada. Como ventaja de su posición geográfica sus usuarios accederían fácilmente a un conjunto diverso de fuentes de materias prima (arcillas, agua, combustibles, etc.). En suma, con las evidencias edilicias y las recuperadas en estratigrafía, se entendió que se trataba de un sector productivo. A través del estudio de la materialidad cerámica obtenida en contextos de excavación, se estableció la presencia de cerámica de estilos tardíos. En contraste con lo recuperado en los contextos de excavación del sector VI, se identificó alfarería peinada con ausencia de pastas finas.

El sector XII es la tercera posición topográfica estudiada y se localiza sobre el faldeo de la quebrada El Carrizal. El conjunto arquitectónico, compuesto por diversas estructuras, se emplaza sobre un terreno en pendiente interrumpido por profundas cárcavas. En función de su entorno natural y su composición edilicia se designó al sector como un área de asentamiento y defensa del poblado. A diferencia de los sectores anteriormente descritos, desde el sector XII se accede a una cuenca visual sectorial orientada hacia el Este y Sur del paisaje. Del relevamiento arquitectónico se pudo determinar el empleo de técnicas constructivas que aseguraran la estabilidad estructural de los edificios sobre un terreno inestable. Al igual que en el sector $\mathrm{VI}$ se hallaron muros internos en algunos recintos que presentaban sus cantos alineados.

Espacialmente, el sector VI presenta características distintivas como el control de la circulación hacia ambas quebradas, visualización hacia los cuatro puntos cardinales y la táctica defensiva que implica la localización sobre una cima elevada. Desde una mirada de lo material no se hallaron registros directos de actividades defensivas o productivas. Es así como se habría delegado en el segmento social allí residente el control de las actividades que involucrarían la vigilancia, administración del asentamiento, entre otras.

\section{Discusión}

A lo largo del asentamiento El Carmen 1 se observaron recursos espaciales con capacidad de portar y transmitir capital cultural (Bourdieu, 1983). Los habitantes del asentamiento estaban parcelados en quebradas, en sectores, en barrios y probablemente en familias. También sus actividades productivas estaban distribuidas. La materialidad ordenaba la vida social en el asentamiento 
(Miller, 2005). Las personas vivían en dos quebradas, a diferentes alturas, residían en diferentes construcciones manufacturadas con variedad de recursos arquitectónicos y también accedían a distintos tipos de bienes culturales. El acceso de algunas familias a una gama alta de materialidades como: obras edilicias con cantos alineados en zonas específicas del paisaje, segregación espacial simbólica y estratégica, acceso a alfarería con iconografía de notable carga simbólica, consumo de vajilla de servicio fina y acceso a variados recursos alimenticios tanto agrícolas como productos ganaderos, indicaría que la cultura material no era homogénea ni circulaba horizontalmente en todas las viviendas.

El paisaje construido y la cultura material se transformarían en capitales culturales aprovechables por un gran hombre para comunicar y perpetuar la ideología. Y como todo lo que es visible también es simbólico se habría visibilizado la desigualdad. Se habría monumentalizado la cultura material (Criado-Boado, 1993) manifestando una sociedad dividida y dedicada a la producción de excedentes. De esta manera, se habría necesitado garantizar el terreno suficiente para la producción de las utilidades ineludibles para asegurar la supervivencia y reproducción (ParceroOubiña, 2000). De la necesidad de asociar los medios de producción con las tierras se habría vuelto el paisaje un territorio (Criado-Boado, 1993). A su vez, habría impreso asimetría en las relaciones humanas espaciales ya que la territorialidad es una de las primeras formas que adopta el poder (Sack, 1986).

Dentro de un escenario de conflicto generalizado y tensión a nivel regional, el gran hombre habría sido funcional para dirigir a la colectividad y esencial para la cohesión interna y la resolución de distintos tipos de conflictos -disputas internas, negociaciones de alianzas intergrupales, comercio, ceremonias- (Johnson y Earle, 2003). A pesar de que este segmento social -al cual pertenecía el jefe- estuviera desligado de las actividades productivas, administraba y distribuía los bienes y recursos y mediaba el intercambio entre facciones, entre las quebradas que desarrollaban actividades complementarias: agrícolas y pastoriles.

Ante una coyuntura sociopolítica hostil, el gran hombre y su elite gobernante se habrían aprovechado de la idea de conflicto y tensión para regular y legitimar su posición. Su poder ya no dependería únicamente de su gestión e iniciativa personal, sino que la coyuntura política habría contribuido al fortalecimiento de su figura. Es de esta manera que la heterogeneidad material y espacial manifestada habría sido el canal comunicativo encontrado por la elite para acrecentar su empoderamiento.

\section{Referencias citadas}

" Bourdieu, P. (1983). Poder, Derecho y Clases Sociales. Bilbao: Desclée de Brouwer.

"Coll Moritán, V., Cantarelli, V. y Nastri, J. (2015). El Carmen 1, un poblado Intermedio Tardío en la Sierra del Cajón (Prov. De Tucumán). Revista del Museo de Antropología, 8(1), 105-114.

»Criado-Boado, F. (1993). Límites y posibilidades de la arqueología del paisaje. Spal, 2, 9-55.

» Johnson, A. y Earle, T. (2003). La evolución de las sociedades humanas. Barcelona: Ariel Prehistoria.

» Lorandi,A.M.yDe Hoyos, M.(1995).Complementariedad económica en los Valles Calchaquíes y del Cajón. Siglos XV-XVII. En L. Escobari de Querejazu (Ed.), Colonización agrícola y ganadera en América. Siglos XV-XVII. Su impacto en la población aborigen (pp. 285-414). Quito: ABYA-YALA.

» Nastri, J. (1997-1998). Patrones de asentamiento prehispánico tardío en el Suroeste del Valle de Santa María (Noroeste Argentino). Relaciones de la Sociedad Argentina de Antropología, XXII-XXIII, 247-270.

» Miller, D. (2005). Materiality. Durham: Duke University Press.

» Parcero-Oubiña, C. (200o). La construcción del paisaje social en la Edad del Hierro del Noroeste Ibérico. (Tesis Doctoral inédita), Universidad de Santiago de Compostela, España.

" Sack, R. (1986). Human Territoriality: Its Theory and history. Cambridge: Cambridge University Press.

» Tarragó, M. (1987). Sociedad y sistema de asentamiento en Yocavil. Cuadernos del Instituto Nacional de Antropología, 12, 179-169.

» Tarragó, M. (1999). Las sociedades del Sudeste andino. En T. Rojas Rabiela, J. V. Murra y G. Carrera Damas (Eds.), Historia general de América Latina. Las sociedades originarias (Volumen 1) (pp. 456-48o). México: Organización de las Naciones Unidas para la Educación, la ciencia y la Cultura-Editorial Trotta. 